\title{
Ethanol Enhances Glutamate Transmission by Retrograde Dopamine Signaling in a Postsynaptic Neuron/Synaptic Bouton Preparation From the Ventral Tegmental Area
}

\author{
Chunyu Deng', Ke-Yong Li', Chunyi Zhou' and Jiang-Hong Ye*,1,2 \\ 'Department of Anesthesiology, University of Medicine and Dentistry of New Jersey, New Jersey Medical School, Newark, NJ, USA; ${ }^{2}$ Departments \\ of Pharmacology and Physiology, University of Medicine and Dentistry of New Jersey, New Jersey Medical School, Newark, NJ, USA
}

\begin{abstract}
It is well documented that somatodendritically released dopamine is important in the excitability and synaptic transmission of midbrain dopaminergic neurons. Recently we showed that in midbrain slices, acute ethanol exposure facilitates glutamatergic transmission onto dopaminergic neurons in the ventral tegmental area (VTA). The VTA is a brain region critical to the rewarding effects of abused drugs, including ethanol. We hypothesized that ethanol facilitation might result from an increase in somatodendritically released dopamine, which acts retrogradely on dopamine $D_{\text {| }}$ receptors on glutamate-releasing axons and consequently leads to an increase in glutamate release onto dopaminergic neurons. To further test this hypothesis and to examine whether ethanol facilitation can occur at the singlecell level, VTA neurons were freshly isolated from rat brains using an enzyme-free procedure. These isolated neurons retain functional synaptic terminals, including those that release glutamate. Spontaneous excitatory postsynaptic currents (sEPSCs) mediated by glutamate $\alpha$-amino-3-hydroxy-5-methylisoxazole-4-propionic acid receptors were recorded from these freshly isolated putative dopaminergic neurons. We found that acute application of clinically relevant concentrations of ethanol ( $10-80 \mathrm{mM})$ significantly facilitated the frequency of sEPSCs but not their mean amplitude. Ethanol facilitation was mimicked by the D, agonist SKF 38393 and by the dopamine uptake blocker GBR 12935 but was blocked by the D, antagonist SKF 83566, and by depleting dopamine stores with reserpine, as well as by chelating postsynaptic calcium with BAPTA. Furthermore, the sodium channel blocker tetrodotoxin eliminated the facilitation of sEPSCs induced by ethanol but not by SKF 38393. These results constitute the first evidence from single isolated cells of ethanol facilitation of glutamate transmission to dopaminergic neurons in the VTA. In addition, we show that ethanol facilitation has a postsynaptic origin and a presynaptic locus. Furthermore, ethanol stimulation of a single dopaminergic neuron is capable of eliciting the release of somatodendritic dopamine, which is sufficient to influence glutamatergic transmission at individual synapses.

Neuropsychopharmacology (2009) 34, 1233-1244; doi: I0.1038/npp.2008.143; published online 10 September 2008
\end{abstract}

Keywords: addiction and substance abuse; alcohol and alcoholism; glutamate; dopamine

\section{INTRODUCTION}

In the ventral tegmental area (VTA) and substantia nigra, dopaminergic (DAergic) neurons can release dopamine somatodendritically (Bjorklund and Lindvall, 1975; Geffen et al, 1976; Cheramy et al, 1981). Dopamine acts on two families of receptors, $\mathrm{D}_{1}$-like (consisting of dopamine $\mathrm{D}_{1}$ and $D_{5}$ receptors) and $D_{2}$-like $\left(D_{2}, D_{3}\right.$, and $D_{4}$ receptors). $D_{1}$ and $D_{2}$ receptors $\left(D_{1} R\right.$ and $\left.D_{2} R\right)$ exert opposite effects on the same signaling pathway, with $\mathrm{D}_{1}$ Rs positively and $\mathrm{D}_{2} \mathrm{Rs}$ negatively affecting adenylyl cyclase. It has been well

*Correspondence: Dr J-H Ye, Department of Anesthesiology, University of Medicine and Dentistry of New Jersey, New Jersey Medical School, I 85 South Orange Avenue, Newark, NJ 07 I03-27I4, USA, Tel: + I 973972 1866, Fax: + I 9739724172 ,

E-mail: ye@umdnj.edu

Received 26 February 2008; revised 7 August 2008; accepted 8 August 2008 documented that somatodendritic dopamine is important in the excitability of DAergic neurons through the activation of $\mathrm{D}_{2}$ autoreceptors in the postsynaptic membrane of the DAergic neurons (Aghajanian and Bunney, 1977; Cragg and Greenfield, 1997; Tepper et al, 1997). Nevertheless, somatodendritic dopamine can also function as a rapid, retrograde signal that activates dopamine receptors on synaptic terminals and regulates synaptic transmission (Abarca et al, 1995; Koga and Momiyama, 2000).

Excitatory synaptic input mediated by glutamate is a key component in the regulation of DAergic cell excitability (Overton and Clark, 1997). $D_{1}$ Rs are situated on glutamatergic synaptic terminals on VTA DAergic neurons but not on the postsynaptic membrane of the DAergic neurons ( $\mathrm{Lu}$ and Hagg, 1997). A previous in vivo study demonstrated that stimulation of the $D_{1}$ Rs increases glutamate release in the VTA (Kalivas and Duffy, 1995). However, it is unknown whether dopamine released from the somatodendritic area 
of an isolated cell can stimulate the $\mathrm{D}_{1} \mathrm{Rs}$ on the glutamatergic synapses on the same DAergic neurons.

The mechanisms underlying alcohol addiction are unclear, but it has been well documented that the glutamatergic and DAergic systems may be critical. Ethanol suppresses glutamatergic transmission in several brain regions (Siggins et al, 2005). Nevertheless, in a recent study in midbrain slices, we found that acute ethanol facilitates glutamatergic transmission in the VTA, a key region in the brain reward system (Xiao et al, 2008). We hypothesize that ethanol facilitation might be mediated by somatodendritically released dopamine, which retrogradely activates the $D_{1} R s$ on the glutamate-releasing terminals on the DAergic neurons to increase glutamate release. However, it is unknown whether ethanol facilitation can occur at the single cell level.

To determine whether ethanol facilitation can occur at the single cell level, we took advantage of a highly reduced preparation consisting of an isolated postsynaptic neuron from the VTA and attached glutamatergic presynaptic terminals. We examined the effects of ethanol on spontaneous excitatory postsynaptic currents (sEPSCs) mediated by glutamate $\alpha$-amino-3-hydroxy-5-methylisoxazole-4-propionic acid (AMPA) receptors and demonstrated that ethanol at pharmacologically relevant concentrations (10$80 \mathrm{mM}$ ) significantly increased sEPSC frequency in the single cell preparation.

\section{MATERIALS AND METHODS}

\section{Slice Preparation and Mechanical Dissociation}

The midbrain slices were prepared as described previously by Ye et al (2004, 2006). Sprague-Dawley rats (aged 10-20 postnatal days) were anesthetized and then killed by decapitation. Coronal midbrain slices $(300 \mu \mathrm{m}$ thick) were cut using a VF-200 slicer (Precisionary Instruments Inc., Greenville, NC). Slices were prepared in an ice-cold glycerol-based artificial cerebrospinal fluid (GACSF) containing $250 \mathrm{mM}$ glycerol, $1.6 \mathrm{mM} \mathrm{KCl}, 1.2 \mathrm{mM} \mathrm{NaH}_{2} \mathrm{PO}_{4}$, $1.2 \mathrm{mM} \mathrm{MgCl} 2,2.4 \mathrm{mM} \mathrm{CaCl}_{2}, 25 \mathrm{mM} \mathrm{NaHCO}$, and $11 \mathrm{mM}$ glucose, and saturated with $95 \% \mathrm{O}_{2} / 5 \% \mathrm{CO}_{2}$ (carbogen; Ye et al, 2006). Slices (two per animal) were allowed to recover for at least $1 \mathrm{~h}$ in a holding chamber at room temperature $\left(22-24^{\circ} \mathrm{C}\right)$ in carbogen-saturated regular artificial cerebrospinal fluid, which has the same composition as GACSF, except that glycerol was replaced by $125 \mathrm{mM} \mathrm{NaCl}$.

Neurons with functional presynaptic terminals attached were obtained by mechanical dissociation (Figure 1a and b), as previously described (Akaike and Moorhouse, 2003), with some modifications (Ye et al, 2004, 2006). Briefly, a midbrain slice was transferred to a $35 \mathrm{~mm}$ culture dish (Falcon, Rutherford, NJ, USA) and held down with a flat U-shape wire. The dish was filled with standard external solution containing $140 \mathrm{mM} \mathrm{NaCl}, 5 \mathrm{mM} \mathrm{KCl}, 2 \mathrm{mM} \mathrm{CaCl}_{2}$, $1 \mathrm{mM} \mathrm{MgCl}_{2}, 10 \mathrm{mM}$ HEPES, and $10 \mathrm{mM}$ glucose ( $320 \mathrm{mOsm}, \mathrm{pH}$ adjusted to 7.3 with Tris base). Under an inverted microscope (Nikon Diaphot, Tokyo, Japan), VTA was identified. A heavily fire-polished pipette, lightly touched the surface of the VTA, and vibrated horizontally at $15-20 \mathrm{~Hz}$ for $2-5 \mathrm{~min}$ using a homemade device. Finally, the slice was removed. After $20 \mathrm{~min}$, isolated neurons that
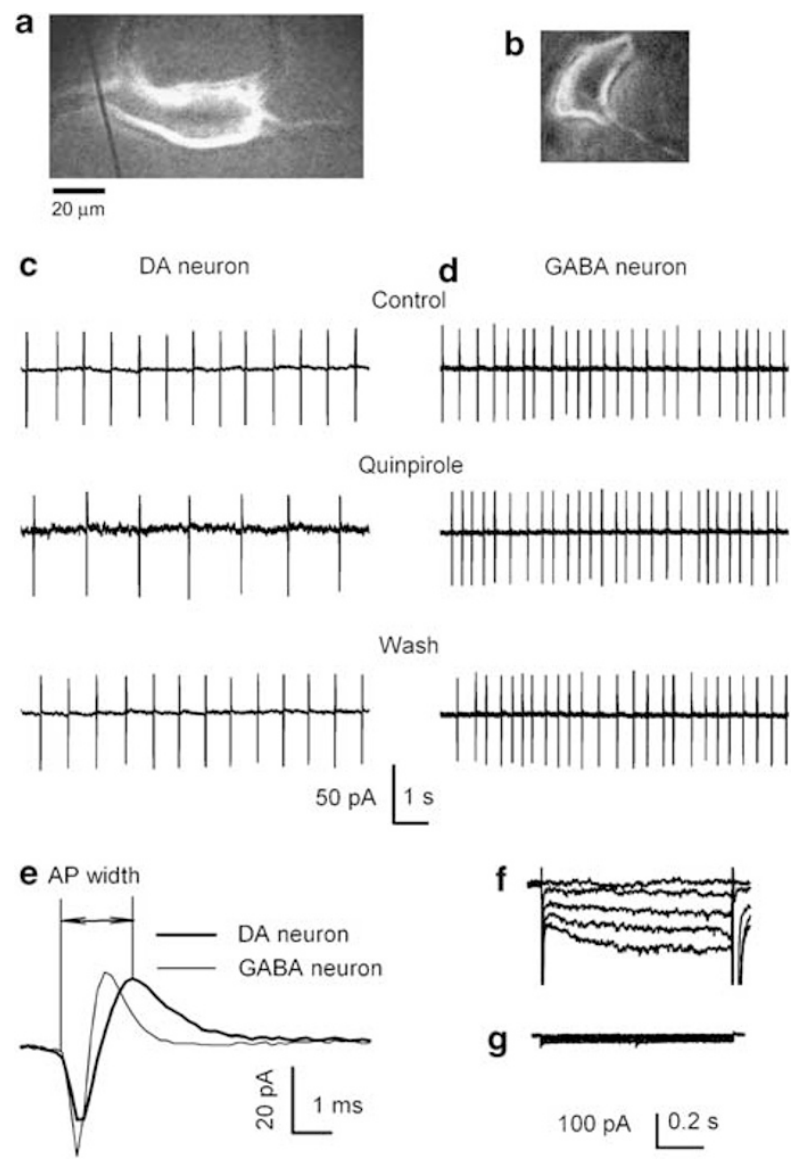

Figure I Identification of DAergic neurons. Photomicrograph of a mechanically dissociated putative DAergic neuron (a) and a putative GABAergic neuron (b). The much reduced dendritic arbors of such cells facilitate space clamp. Spontaneous firings recorded with loose-patch cellattached mode showing the inhibitory response of the DAergic neuron (c) and the no response of the GABAergic neuron (d) to the $D_{2 / 3}$ receptor antagonist, quinpirole. (e) Comparison of single spontaneous action potentials recorded from a putative DAergic neuron (thicker line, with a half-width of $1.7 \mathrm{~ms}$ ) and a putative GABAegic neuron (thinner line, with a half-width of I.I ms). Under voltage clamp, the currents induced in such a DAergic cell by a series of hyperpolarizing voltage pulses (the $10 \mathrm{mV}$ steps to $-110 \mathrm{mV}$ ) show the prominent $I_{\mathrm{h}}$ of the DAergic ( $\mathrm{f}$ ) but not in the GABAergic (g) neuron.

adhered to the bottom of the dish were used for electrophysiological recordings. These mechanically dissociated neurons often preserved some functional nerve terminals, including those that release glutamate (Yamanaka et al, 2002; Akaike and Moorhouse, 2003; Ye et al, 2004; Zhu and Lovinger, 2005; Jang et al, 2006).

\section{Electrophysiological Recordings}

Electrical signals were obtained in whole-cell and loosepatch cell-attached patch clamp configurations with an Axon 200B amplifier (Molecular Devices Co., Union City, CA, USA), a Digidata 1320A A/D converter (Molecular Devices Co.), and pCLAMP 9.2 software (Molecular Devices Co.). Data were filtered at $1 \mathrm{kHz}$ and sampled at $5 \mathrm{kHz}$. The patch electrodes had a resistance of 2-5 M 2 when filled with the pipette solution containing: $135 \mathrm{mM} \mathrm{CsF}, 5 \mathrm{mM} \mathrm{KCl}$, $2 \mathrm{mM} \mathrm{MgCl}, 10 \mathrm{mM}$ HEPES, $2 \mathrm{mM} \mathrm{Mg} \mathrm{ATP}$, and $0.2 \mathrm{mM}$ 
GTP. The $\mathrm{pH}$ of the pipette solution was adjusted to 7.2 with Tris base. All sEPSCs were recorded in the presence of $10 \mu \mathrm{M}$ bicuculline at a holding potential $\left(V_{\mathrm{H}}\right)$ of $-65 \mathrm{mV}$.

\section{Chemicals and Applications}

The chemicals, including bicuculline, 6,7-dinitroquinoxaline-2,3-dione (DNQX), reserpine, tetrodotoxin (TTX), [D$\mathrm{Ala}^{2}, \mathrm{~N}$-Me-Phe ${ }^{4}, \mathrm{Gly}^{5}$-ol] enkephalin (DAMGO) were obtained from Sigma-Aldrich Chemical Company (St Louis, MO, USA). (-)-Quinpirole hydrochloride, GBR 12935, $\mathrm{N}$ allyl- $( \pm)$-SKF 38393, and ( \pm )-SKF 83566 were from Tocris Bioscience (Ellisville, MO, USA). Ethanol (95\%, prepared from grain) was from Pharmco (Brookfield, CT, USA) and stored in glass bottles. Drugs were added to the superfusate applied to the cell using a fast perfusion system ( $\mathrm{Y}$ tube). Solutions in the vicinity of a neuron can be completely exchanged within $40 \mathrm{~ms}$ without damaging the seal (Zhou et al, 2006).

\section{Data Analysis}

sEPSCs and miniature excitatory postsynaptic currents (mEPSCs) were counted and analyzed with Clampfit 9.2 (Molecular Devices Co.); sEPSCs and mEPSCs were screened automatically (6 pA amplitude threshold), checked visually, and accepted or rejected according to their rise and decay times. The frequency and amplitude of all events, during and after drug application, were normalized to the mean of the values observed during the initial control period. Cumulative probability plots of the incidences of various interevent intervals and amplitudes, recorded under different conditions from the same neuron, were compared using the Kolmogorov-Smirnov (K-S) test. For other plots, data obtained over a $0.5-2$ min period at the peak of a drug response were normalized to the average values of frequency (or amplitude) of the sEPSC (or mEPSC) recorded during the initial control period (1-4 min). Data are expressed as means ( \pm SEM). The statistical significance of drug effects was assessed by a paired two-tailed $t$-test on normalized data. For effects of multiple drug concentrations an appropriate one-way analysis of variance (ANOVA) was used. Statistical analyses were performed with SigmaStat (SPSS, Chicago, IL). Values of $p<0.05$ were considered significant.

\section{RESULTS}

\section{Identification of VTA DAergic Neurons}

DAergic neurons in the VTA were identified on the basis of their well-established pharmacological and electrophysiological properties (Lacey et al, 1989; Zhou et al, 2006; Xiao et al, 2007, 2008). Figure 1 shows sample traces of spontaneous discharges of a putative DAergic neuron (Figure 1c) and a putative GABAergic neuron (Figure 1d) recorded in the cell-attached mode. Although the dopamine $\mathrm{D}_{2} / \mathrm{D}_{3}$ receptor agonist quinpirole inhibited ongoing discharges of the putative DAergic neurons, the $\mu$-opioid receptor agonist Tyr-D-Ala-Gly- $\mathrm{N}$-Me-Phe-Gly-ol enkephalin (DAMGO) had no effect (data not shown). In contrast, quinpirole had no effect on the ongoing discharges of the
GABAergic neuron (Figure 1d). The spontaneous pacemaker $(1-5 \mathrm{~Hz})$ firing with spikes exhibiting action potential widths of $\geqslant 1.2 \mathrm{~ms}$ (Figure $1 \mathrm{e}$, measured in cellattached mode from the initial inward current to the peak of the outward current) is a marker of tyrosine hydroxylase expressing principle cells (Ford et al, 2006; Xiao et al, 2007, 2008). In addition, DAergic neurons exhibited a prominent hyperpolarization-activated inward current $\left(I_{h}\right)$ in response to a series of voltage steps from -70 to $-110 \mathrm{mV}$ (with decrement of $10 \mathrm{mV}$ ) when recorded under whole-cell voltage clamp conditions (Figure 1f), whereas VTA GABAergic neurons have no prominent $I_{\mathrm{h}}$ (Figure 1g; Jones and Kauer, 1999). These are characteristic electrophysiological properties of DAergic neurons. The following experiments were carried out on putative DAergic neurons identified according to the aforementioned characteristics.

The identification of VTA DAergic neurons by their responses to quinpirole and the expression of $I_{\mathrm{h}}$ has been challenged: $I_{\mathrm{h}}$ is present in $\sim 60 \%$ of VTA DAergic neurons (Margolis et al, 2006). Nevertheless, as our result relies on somatodendritically released dopamine, it is highly unlikely that the recordings are from nonDAergic neurons, because of the fact that there is no DAergic axonal projection in the VTA (Tepper et al, 1987; Adell and Artigas, 2004).

\section{Ethanol Raises sEPSC Frequency in Mechanically Dissociated DAergic Neurons}

In a recent study in midbrain slices, we found that clinically relevant concentrations of ethanol (10-80 mM) increased glutamatergic transmission (Xiao et al, 2008). To determine whether this effect could be observed in isolated neurons, we repeated the experiments in mechanically dissociated neurons ('nerve-bouton' preparations). Such preparations combine several advantages: good space clamp, preservation of some functioning synaptic terminals, including those that release glutamate as well as better control of the surrounding solution (Akaike and Moorhouse, 2003; Ye et al, 2004; Zhu and Lovinger, 2005). sEPSCs were recorded in the presence of the $\mathrm{GABA}_{\mathrm{A}}$ receptor antagonist bicuculline $(10 \mu \mathrm{M})$ at a holding potential of $-65 \mathrm{mV}$. In addition, the use of the CsF-based internal solution in these experiments suppressed $\mathrm{GABA}_{\mathrm{A}}$ receptor-mediated postsynaptic currents (Bormann et al, 1987). Under these conditions, all the spontaneous synaptic events were reversibly abolished by the antagonist of AMPA/kainate receptor DNQX $(10 \mu \mathrm{M})$, indicating that they are AMPA/ kainate receptor-mediated sEPSCs (Figure $2 \mathrm{a}$ and $\mathrm{b}$ ).

After obtaining stable control sEPSCs, $40 \mathrm{mM}$ ethanol was applied to the cell using a fast perfusion system (Y tube). In keeping with the results from brain slices, $40 \mathrm{mM}$ ethanol robustly increased the frequency of sEPSCs in the dissociated neurons. This effect, which was reversible upon washout of ethanol, is illustrated in Figure $2 \mathrm{a}-\mathrm{c}$ (normalized increase by $91 \pm 16 \%$; from $1.5 \pm 0.4 \mathrm{~Hz}$ in control to $2.6 \pm 0.5 \mathrm{~Hz}$ in ethanol; $n=5, p<0.001$, by paired $t$-test). It is further illustrated in Figure $2 \mathrm{~d}$ by the large increase in the incidence of shorter intervals between successive sEPSCs. Additional tests with a range of ethanol concentration indicate that the effect of ethanol on sEPSC frequency was dependent on its concentrations. Specifically, 10, 20, and $80 \mathrm{mM}$ increased the frequency by $29 \pm 10 \% \quad(n=4$, 
a

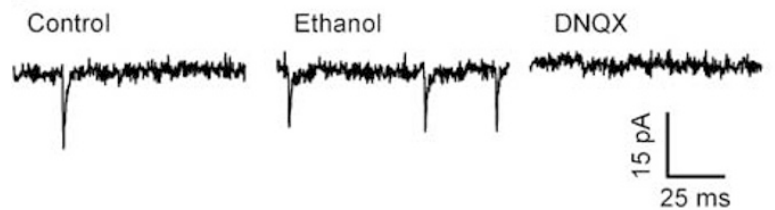

b

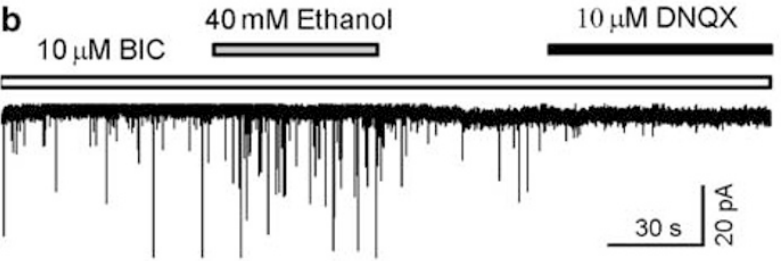

C
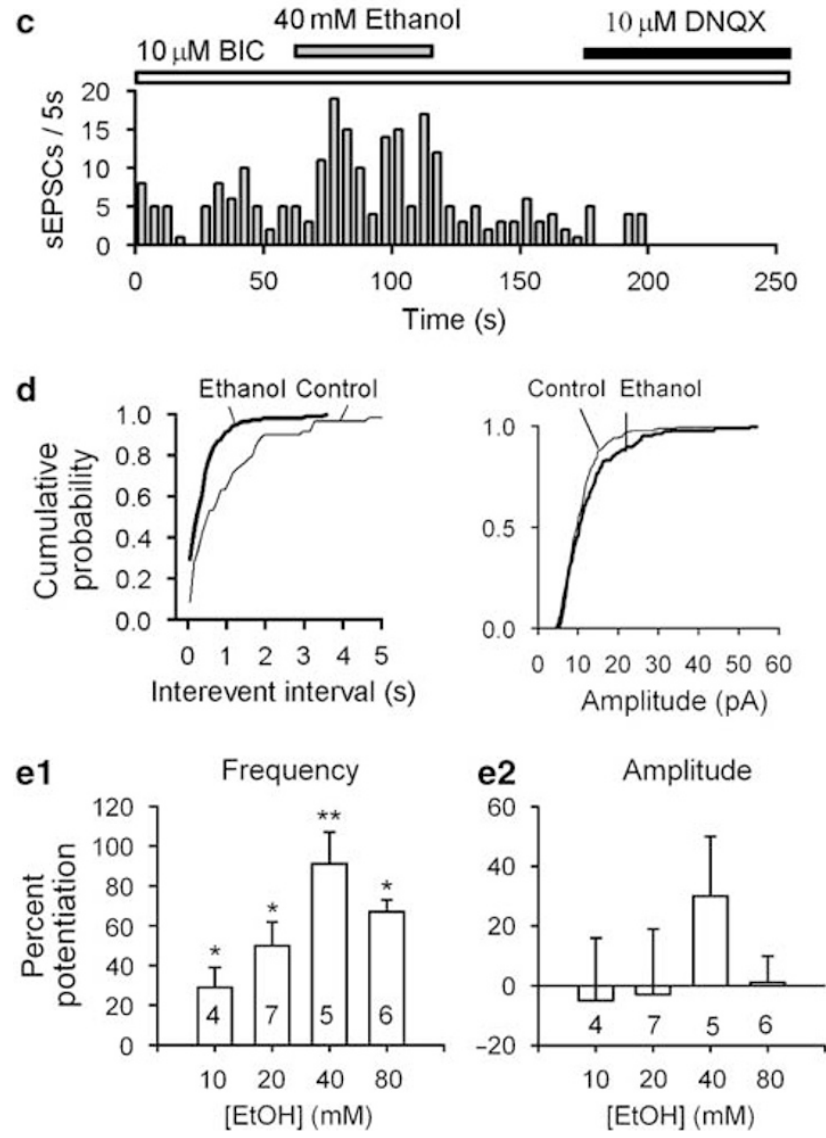

Figure 2 Ethanol enhances frequency of spontaneous excitatory postsynaptic currents (sEPSCs) recorded from mechanically dissociated DAergic neurons. SEPSCs were recorded in the presence of bicuculline $(10 \mu \mathrm{M})$ at a $V_{H}$ of $-65 \mathrm{mV}$. The frequency of sEPSCs was increased by $40 \mathrm{mM}$ ethanol and the sEPSCs were eliminated by $10 \mu \mathrm{M}$ DNQX $(\mathrm{a}-\mathrm{c})$. (c) Time course of ethanol-induced enhancement of sEPSC frequency in one experiment. (d) Cumulative probability of sEPSC interevent intervals (left panel) and current amplitudes (right panel) of the same data. (e) Dosedependent potentiation of sEPSC frequency $\left(e_{1}\right)$, but unaltered amplitude ( $e_{2}$; mean \pm SEM, number of cells in each group is indicated). ${ }^{*} p<0.05$, *** $p<0.0$ I, paired $t$-test for ethanol application vs pre-ethanol control.

$p=0.02), 50 \pm 12 \%(n=7, p<0.05)$, and $67 \pm 6 \% \quad(n=6$, $p=0.04)$, respectively. In contrast, ethanol did not significantly change sEPSC amplitude. 10, 20, 40, and $80 \mathrm{mM}$ ethanol altered the amplitude of sEPSCs by $-5 \pm 21$, $-3 \pm 22,30 \pm 22$, and $1 \pm 9 \%$, respectively. This finding is a
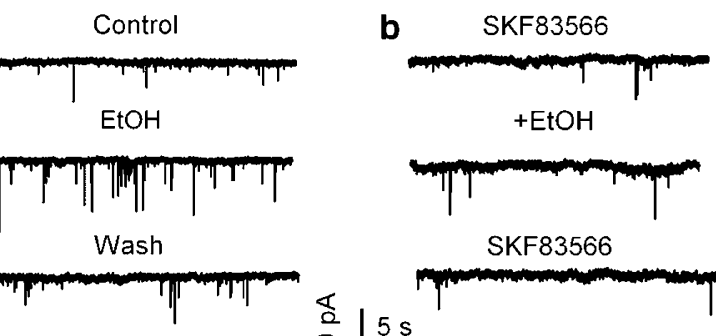

$+\mathrm{EtOH}$

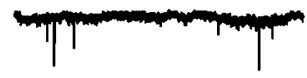

SKF83566

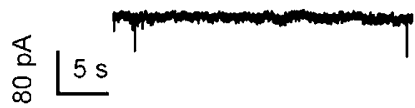

C

Frequency

d Amplitude
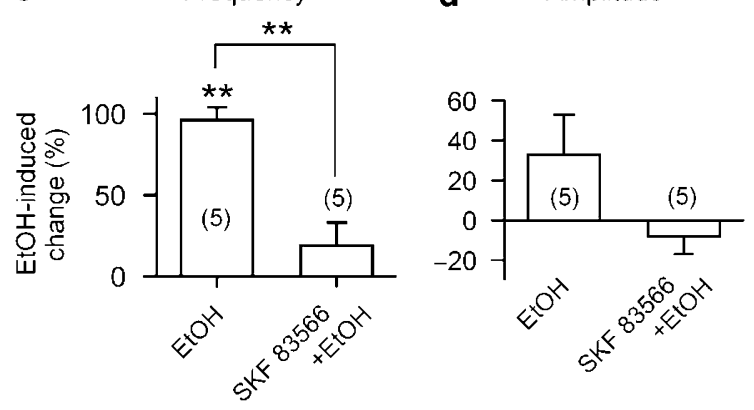

Figure 3 Effect of the $D_{1} R$ antagonist on ethanol facilitation of sEPSCs. (a) Current traces show that ethanol enhancement of sEPSCs was eliminated by $10 \mu \mathrm{M}$ SKF $83566(D, R$ antagonist; b). Summary of ethanolinduced changes (\%) in sEPSC frequency (c) and amplitude (d) in the absence $(\mathrm{EtOH})$ and the presence of SKF 83566 (SKF $83566+\mathrm{EtOH}$, data from six cells). ${ }^{*} * 0.01$, paired $t$-test for ethanol application vs preethanol control.

the first electrophysiological demonstration of the potentiating effect of acute ethanol on glutamatergic transmission at the single cell level.

\section{Effects of Dopamine $D_{1}$-Like Antagonist on Ethanol Facilitation of sEPSCs}

Systemic administration of ethanol increases somatodendritic dopamine release in the VTA in vivo (Campbell et al, 1996). In the VTA, $D_{1}$ Rs are expressed on glutamatergic axons but not on the soma of DAergic neurons ( $\mathrm{Lu}$ and Hagg, 1997). Microdialysis data have shown that $D_{1}$-like agonists increase the extracellular levels of glutamate in the VTA (Kalivas and Duffy, 1995). To test for the possible involvement of $D_{1} R s$ in ethanol-induced enhancement of glutamatergic transmission, we compared the effect of ethanol on sEPSC frequency in the absence and the presence of the $\mathrm{D}_{1}$ antagonist SKF $83566(10 \mu \mathrm{M})$. The application of $40 \mathrm{mM}$ ethanol robustly increased sEPSC frequency (Figure 3a). Though ineffective when applied alone, SKF $83566(10 \mu \mathrm{M})$ suppressed ethanol $(40 \mathrm{mM})$-induced in crease in sEPSC frequency (Figure $3 b$ ). Specifically, ethanol $(40 \mathrm{mM})$ alone increased sEPSC frequency by $96 \pm 8 \%$ $(n=5, p<0.01)$ and by $19 \pm 11 \%(n=5, p=0.274)$ in the absence and the presence of SKF $83566(10 \mu \mathrm{M})$, respectively (Figure $3 \mathrm{c}$ ). Ethanol ( $40 \mathrm{mM}$ ) has no significant effect on sEPSC amplitude both in the absence and the presence of SKF $83566(10 \mu \mathrm{M})$, by $23 \pm 17 \%(p=0.41, n=5)$ and $-7 \pm 7 \%(p=0.26, n=5)$, respectively (Figure $3 \mathrm{~d})$. These results suggest that presynaptic dopamine $\mathrm{D}_{1}$-like receptors 
are essential in ethanol facilitation of glutamatergic transmission.

\section{Dopamine $D_{1}$-Like Agonist Increases the Frequency of} sEPSCs in Dissociated DAergic Neurons

To further establish the involvement of $D_{1}$ Rs, we tested the effects of the $\mathrm{D}_{1}$ agonist SKF 38393 on sEPSCs in dissociated putative DAergic neurons. SKF $38393(10 \mu \mathrm{M})$ significantly increased sEPSC frequency by $106 \pm 19 \%$ (control, $1.0 \pm 0.1 \mathrm{~Hz}$; SKF 38393, $2.0 \pm 0.4 \mathrm{~Hz} ; n=5, p=0.01$; Figure $4 \mathrm{~A}$ and $\mathrm{B})$, and shortened intervals between successive sEPSCs (K-S test, $p<0.01$; Figure $4 \mathrm{C})$. However, there was no significant change in the corresponding plot of sEPSC amplitudes (by $-8 \pm 6 \%, n=5, p>0.3$; Figure $4 \mathrm{D}$ ). The facilitation effect was observed to peak within $30 \mathrm{~s}$. Subsequently the frequency of sEPSCs recovered to or slightly lower than the base line level (Figure 4B). Similar phenomenon was observed in five other neurons tested (see also Figure 4F). We next tested the effect of SKF 38393 on mEPSCs in the presence of TTX $(1 \mu \mathrm{M})$. SKF $38393(10 \mu \mathrm{M})$ caused a significant increase of mEPSC frequency by $156 \pm 63 \%$ (basal, $0.8 \pm 0.3 \mathrm{~Hz}, \operatorname{SKF} 38393,2.1 \pm 0.3 \mathrm{~Hz}$, $p<0.01 ; n=6$ ), without changing the amplitude (by $13 \pm 19 \%$, basal, $13 \pm 2 \mathrm{pA}$, SKF $38393,13 \pm 1 \mathrm{pA}, p=0.85$; $n=6$ ). Similar to that for sEPSCs, the response of mEPSC to SKF 38393 desensitized quickly in the continuous presence of SKF 38393 (Figure 4F). These results provide unique
A a Control
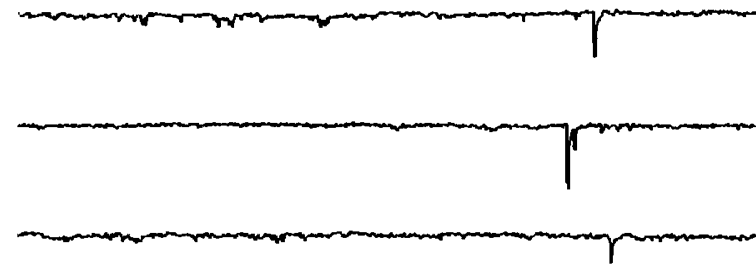

b $\quad$ SKF38393
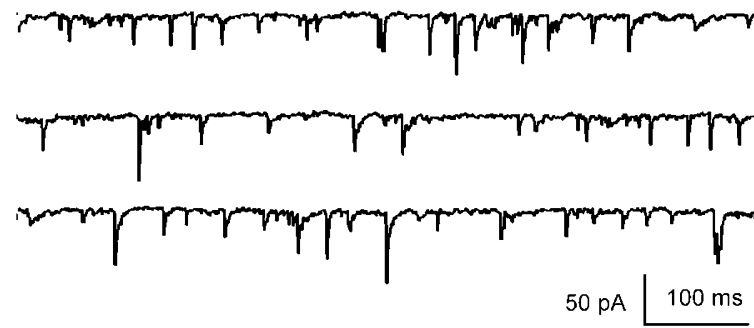

B

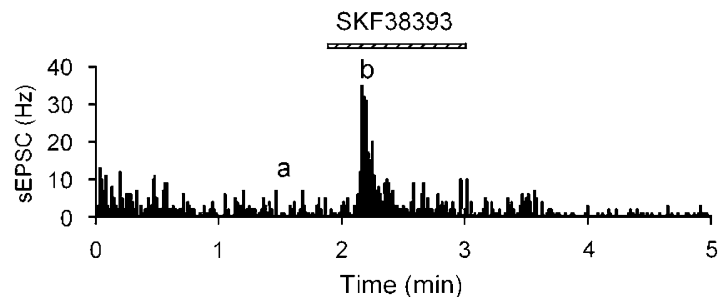

C

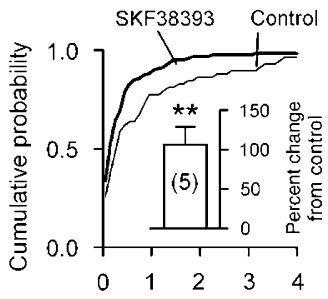

Interevent interval (s)

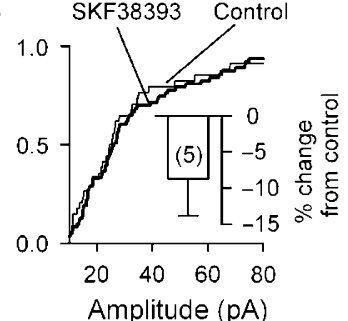

D SKF38393 Control
E a

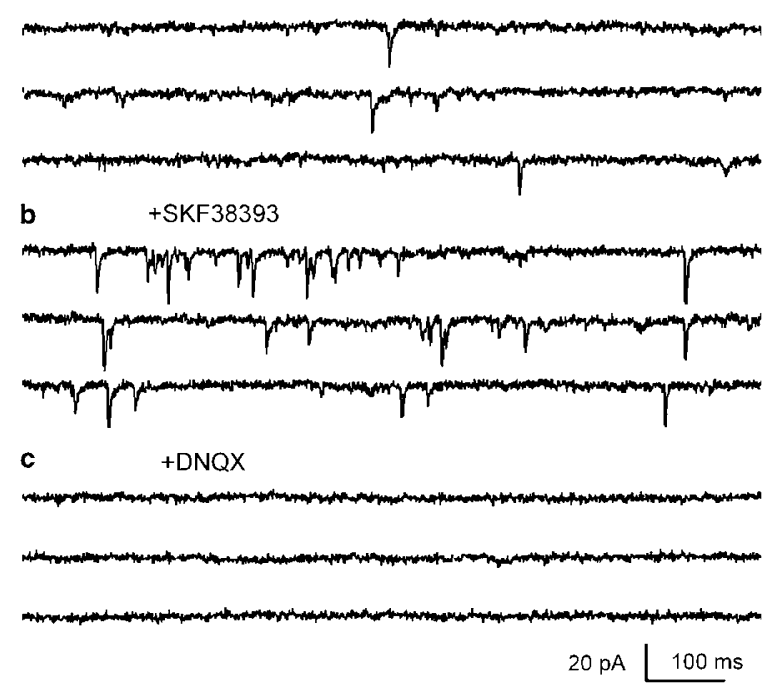

$\mathbf{F}$

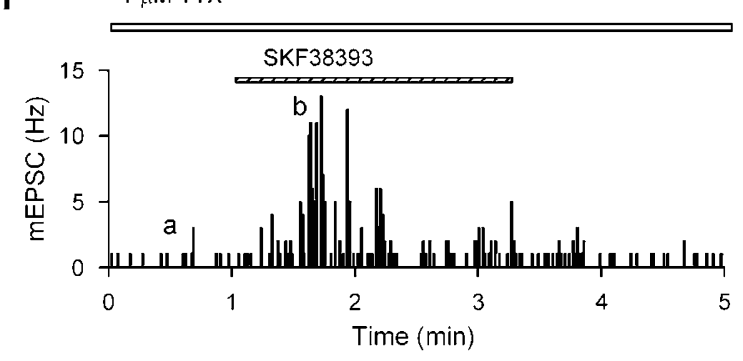

G

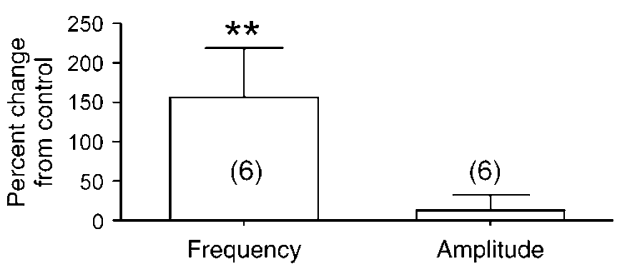

Figure 4 Effect of the $D_{1} R$ agonist on sEPSCs and mEPSCs in isolated neurons. (A) The $D_{1} R$ agonist SKF $38393(10 \mu M)$ increased sEPSC frequency in a putative DAergic neuron in the VTA. (B) Time course of changes induced by SKF 38393. The traces in (A) were taken at times indicated by (a) and (b). The change in frequency is also demonstrated by the much increased incidence of shorter intervals between sEPSCs. A representative cumulative probability plot of interevent interval (C), but there was no associated change in sEPSC amplitudes (D). The inset shows mean \pm SEM of \% changes in sEPSC frequency (C) and amplitude (D) induced by SKF 38393 ( I $0 \mu \mathrm{M} ; n=5$ ). *** $<<0.01$, paired t-test for SKF 38393 application vs pre-SKF 38393. (E) SKF 38393 (I0 $\mu$ M) increased mEPSC frequency in the presence of TTX $(I \mu M)$ in a putative DAergic neuron in the VTA. (F) Time course of changes induced by SKF 38393. The traces in (E) were taken at times indicated by (a) and (b). (G) Summary of results (mean \pm SEM of \% changes) from six cells showing that SKF 38393 $($ I $0 \mu M$ ) significantly increased mEPSC frequency (left column) but not the amplitude (right column). $* * * 00.01$, paired t-test for SKF 38393 application vs pre-SKF 38393. 
electrophysiological evidence indicating that functional $\mathrm{D}_{1}$ Rs exist on glutamatergic terminals, which make synapses on the DAergic neurons in the VTA, and that activation of these presynaptic $D_{1}$ Rs facilitates glutamatergic neurotransmission.

Our results might appear inconsistent with the study in brain slices by Schilstrom et al (2006) reporting that application of the $\mathrm{D}_{1}$ agonist SKF $81297(10 \mu \mathrm{M})$ caused a slight but significant reduction in mEPSC frequency. However, our hypothesis is that the slightly reduction in mEPSC frequency observed by these investigators might be a consequence of $\mathrm{D}_{1} \mathrm{R}$ desensitization (Memo et al, 1982; Balmforth et al, 1990; Cameron and Williams, 1993), because our data show that even in the isolated cells, in which $\mathrm{D}_{1}$ agonist application is much more rapid than that in brain slices, $D_{1} R$ activation induced facilitation of EPSCs desensitized very rapidly. In addition, in the experiments of Schilstrom et al (2006), the effect of SKF 81297 on mEPSCs was determined by the data collected after $10 \mathrm{~min}$ of drug application. Thus, the short increase in mEPSC frequency induced by the $D_{1}$ agonist, if it exists, might have been overlooked in their study. The latter possibility is supported by our recent study showing that SKF 38393 did increase sEPSC frequency in brain slices (Xiao et al, 2008).

\section{Ethanol does not Alter mEPSCs in Mechanically Dissociated DAergic Neurons}

Next, we recorded mEPSCs in the presence of the sodium channel blocker tetrodotoxin (TTX, $1 \mu \mathrm{M}$ ) and bicuculline $(10 \mu \mathrm{M})$. In nerve-bouton preparations, TTX $(1 \mu \mathrm{M})$ sharply decreased sEPSC frequency to $33 \pm 10 \%$ of control (from $3.3 \pm 1.1 \mathrm{~Hz}$ in control to $1.0 \pm 0.5 \mathrm{~Hz}$ in TTX; $n=5, p<0.01$ ) and moderately reduced the amplitude to $73 \pm 5 \%$ of control (from $16 \pm 4 \mathrm{pA}$ in control to $12 \pm 3 \mathrm{pA}$ in TTX; $n=5$, $p>0.05)$.

In the presence of TTX $(1 \mu \mathrm{M})$, the mEPSCs recorded from four nerve-bouton preparations were not sensitive to ethanol, consistent with the observations in brain slices (Xiao et al, 2008). Ethanol $(40 \mathrm{mM})$ increased the frequency of mEPSCs by $11 \pm 7 \%(p=0.33, n=4)$ and the amplitude by $-7 \pm 8 \%(p=0.19 ; n=4$; Figure $5 \mathrm{~A}-\mathrm{D})$.

The effects of TTX suggest that ethanol-induced increase in glutamatergic transmission is not only because of an increase in dopamine released from the postsynaptic cell, as that should not be blocked by TTX in a well-clamped cell. Ethanol might additionally act on a presynaptic site other than that directly affected by the $\mathrm{D}_{1} \mathrm{R}$. It appears that ethanol augments the $\mathrm{D}_{1} \mathrm{R}$-mediated enhancement of glutamate release in a way that is dependent on the presynaptic TTX-sensitive $\mathrm{Na}^{+}$channels. To test this possibility, we examined ethanol-induced augmentation of the SKF 38393-induced enhancement of sEPSCs in the absence and presence of TTX. As expected, in the absence of TTX, the co-application of ethanol (20 mM) and SKF 38393 $(10 \mathrm{nM})$ increased sEPSC frequency by $181.8 \pm 14.6 \%$ $(n=4)$, which is significantly larger than that induced by SKF 38393 (10 nM) alone (by $50.9 \pm 16.0 \%, n=4, p<0.01$ ). Conversely, in the presence of TTX, the co-application of SKF $38393(10 \mathrm{nM})$ and ethanol $(20 \mathrm{mM})$ increased mEPSC
A
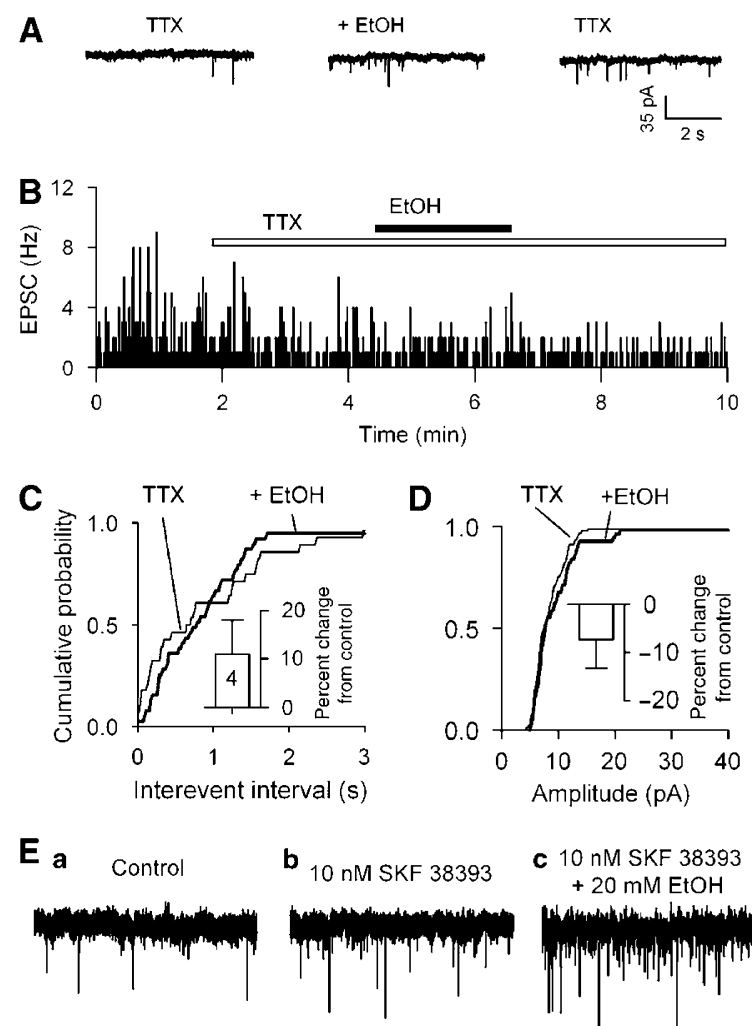

c $10 \mathrm{nM} \mathrm{SKF} 38393$ $+20 \mathrm{mM} \mathrm{EtOH}$
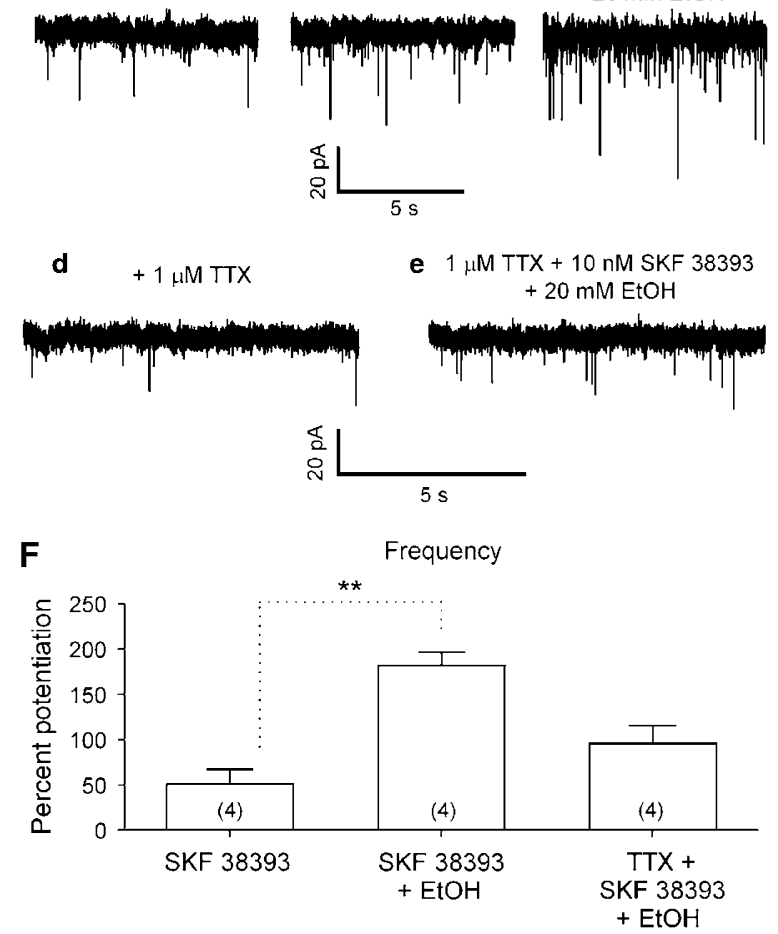

Figure 5 Ethanol has no effect on $m E P S C s$. The mEPSCs were recorded in VTA DAergic neurons at a $V_{H}$ of $-65 \mathrm{mV}$, in the presence of bicuculline $(10 \mu \mathrm{M})$ and tetrodotoxin $(T \mathrm{TX}, \mathrm{I} \mu \mathrm{M})$. (A) Application of $40 \mathrm{mM}$ ethanol did not change the incidence of mEPSCs. (B) Time course of ethanol-induced changes of sEPSC frequency in one experiment. (C, D) Representative cumulative probability plots of intervals between mEPSCs (C) and their amplitudes (D) remained unchanged. Inset: mean data ( \pm SEM, from four neurons) confirm absence of significant effect of ethanol on frequency and amplitude of mEPSCs. (E) Ethanol $(20 \mathrm{mM})$ increased the enhancement of sEPSC frequency induced by $20 \mathrm{nM}$ SKF 38393 (c) but not in the presence (e) of TTX $(\mid \mu M)$. (F) Mean data ( \pm SEM, from four neurons) confirm ethanol $(20 \mathrm{mM})$ increased $20 \mathrm{nM}$ SKF 38393 -induced enhancement of sEPSC frequency in the absence but not in the presence of TTX $(I \mu M)$. ** $p<0.01$, t-test for SKF 38393 application vs SKF 38393 + ethanol. 
frequency by $95.8 \pm 19.4 \%(n=4)$, which is not significantly different from that induced by SKF 38393 alone $(p=0.1$, $n=4$; Figure $5 \mathrm{E}$ and $\mathrm{F}$ ).

\section{Somatodendritic Dopamine Release in the VTA is Essential for the Action of Ethanol}

To determine whether dopamine release is necessary for the action of ethanol, we applied ethanol to nerve-bouton preparations in which dopamine was depleted by reserpine. Because reserpine was dissolved in acetic acid (final concentration $1: 5000, \mathrm{v} / \mathrm{v}$ ), control tests were carried out on neurons isolated from slices pretreated for $>90 \mathrm{~min}$ with this concentration of the vehicle alone. After the treatment with acetic acid, the frequency and amplitude of the sEPSCs were not significantly changed. Ethanol $(40 \mathrm{mM})$ increased sEPSC frequency by $77 \pm 6 \%$ (baseline, $1.0 \pm 0.2 \mathrm{~Hz}$; ethanol, $1.8 \pm 0.4 \mathrm{~Hz}, n=4, p<0.05$, Figure $6 \mathrm{~A}$ and E2). By contrast, in neurons isolated from slices pretreated for similar periods with reserpine $(10 \mu \mathrm{M})$, sEPSC frequency was much lower (see below), and also did not respond to $40 \mathrm{mM}$ ethanol: by $39 \pm 19 \%$ of control (baseline, $0.2 \pm 0.0 \mathrm{~Hz}$; ethanol $0.3 \pm 0.1 \mathrm{~Hz}, n=4, p=0.233$, Figure $6 \mathrm{~B}$ and $\mathrm{E}$ ). These data indicate that the release of dopamine is essential for ethanol-induced facilitation of sEPSCs.

Somatodendritic dopamine release depends on membrane depolarization (Llinas et al, 1984; Grace, 1990). It is augmented following potassium (Kalivas and Duffy, 1991) or veratridine depolarization (Iravani et al, 1996). Therefore we tested whether depolarizing step applied to isolated dopamine neurons can increase sEPSC frequency. A $4 \mathrm{~s}$ depolarizing step from -60 to $0 \mathrm{mV}$ increased sEPSC frequency in 7 out of 13 cells tested (by $52 \pm 18 \%$, prepulse, $1.9 \pm 0.3 \mathrm{~Hz}$; postpulse, $2.9 \pm 0.4 \mathrm{~Hz}, n=7, p<0.05$; Figure $6 C)$. These responses varied widely and may have been complicated by depolarization induced the release of other neurotransmitters/neuromodulators, such as endocannabinoids, which inhibited presynaptic glutamate release in the VTA (Melis et al, 2004).

The release of dopamine in the VTA is $\mathrm{Ca}^{2+}$ dependent (Kalivas and Duffy, 1991; Campbell et al, 1996; Reith et al, 1997), and thus can be prevented or reduced by chelating postsynaptic $\mathrm{Ca}^{2+}$. To further ensure a role for somatodendritic dopamine in ethanol facilitation of sEPSCs, we tested the effect of ethanol $(40 \mathrm{mM})$ on cells recorded with pipette solution containing the $\mathrm{Ca}^{2+}$ chelater BAPTA $(20 \mathrm{mM})$. Under these experimental conditions, ethanol $(40 \mathrm{mM})$ changed neither sEPSC frequency (by $-6 \pm 8 \%$, baseline, $1.8 \pm 0.4 \mathrm{~Hz}$; ethanol, $1.8 \pm 0.5 \mathrm{~Hz}, n=3, p=0.66$; Figure 6D and $\mathrm{E}$ ), nor sEPSCs amplitude (baseline, $34 \pm 4 \mathrm{pA}$; ethanol, $38 \pm 3 \mathrm{pA}, n=3, p=0.29)$. These data indicate that somatodendritic release of dopamine is necessary for ethanolinduced facilitation of sEPSCs.

\section{Blockade of Dopamine Reuptake Raises sEPSC Frequency in Mechanically Dissociated DAergic Neurons}

Previous in vivo evidence indicates that acute administration of ethanol (by intraperitoneal injection) elevates extracellular dopamine levels in the VTA (Campbell et al, 1996; Yan et al, 2005). To elicit a similar rise in local dopamine levels in single neurons, we applied the selective blocker of dopamine transport GBR 12935. Application of GBR $12935(1 \mu \mathrm{M})$ remarkably increased sEPSC frequency by $157 \pm 31 \%$ (control, $0.7 \pm 0.2 \mathrm{~Hz}$; GBR 12935, $1.5 \pm 0.3 \mathrm{~Hz}$; $n=4, p=0.01$, Figure 7b). GBR 12935 had no effect on the mean amplitude of sEPSCs (control, $19 \pm 2$ pA; GBR 12935, $21 \pm 2 \mathrm{pA} ; n=4, p=0.01$, Figure 7c). The effect of GBR 12935 depended on its concentrations. On average, 0.02, 0.2, and $1 \mu \mathrm{M}$ GBR 12935 changed sEPSC frequency by $66 \pm 20 \%$ $(n=5), 85 \pm 18 \%(n=3)$, and $157 \pm 31 \%(n=4)$, respectively (one-way ANOVA, $\mathrm{F}=5,16, p=0.018$ ). This finding shows that a rise in local dopamine levels also mimics the action of ethanol.

Our next step was to investigate the mechanism of GBR 12935-induced facilitation of sEPSC frequency. Application of SKF $83566(10 \mu \mathrm{M})$ alone had no effect on sEPSC frequency (by $3 \pm 2 \%$ of control. Baseline, $0.9 \pm 0.1 \mathrm{~Hz}$; SKF $83566,0.9 \pm 0.1 \mathrm{~Hz} ; n=4, p=0.10$, not illustrated). However, SKF 83566 abolished the enhancement of sEPSC frequency induced by GBR $12935(1 \mu \mathrm{M})$. In the presence of SKF $83566(10 \mu \mathrm{M})$, the sEPSC frequency changed by $2 \pm 4 \%$ (GBR 12935, $1.5 \pm 0.3 \mathrm{~Hz} ; \quad$ GBR $12935+$ SKF 83566, $0.9 \pm 0.2 \mathrm{~Hz} ; n=4, p=0.01$; Figure $7 \mathrm{~b}$ ). These results further indicate that $D_{1} R s$ are essential in dopamine facilitation of glutamatergic transmission to the DAergic neurons in the VTA.

Finally, we reexamined the effects of GBR $12935(1 \mu \mathrm{M})$ and SKF $38393(10 \mu \mathrm{M})$ on cells recorded with pipette solution containing $20 \mathrm{mM}$ BAPTA. Under these experimental conditions, the sEPSCs were virtually identical in the absence and presence of $1 \mu \mathrm{M}$ GBR 12935 (frequency: control, $0.490 \pm 0.129 \mathrm{~Hz} ;$ GBR $12935,0.487 \pm 0.131 \mathrm{~Hz}$, $n=4, \quad p=0.81$; amplitude: control, $27.7 \pm 5.2 \mathrm{pA}$; GBR $1293528.5 \pm 5.7 \mathrm{pA}, \quad n=4, p=0.21)$. Conversely, SKF 38393 increased sEPSC frequency by $101.4 \pm 39.6 \%$ (control, $0.41 \pm 0.12 \mathrm{~Hz}$, SKF 38393, $0.76 \pm 0.17 \mathrm{~Hz} ; n=4 ; p=0.032$ ), without changing their mean amplitude (control, $30.9 \pm 2.6 \mathrm{pA} ;$ SKF $38393,31.3 \pm 3.8 \mathrm{pA} ; n=4, \quad p=0.94$; Figure $7 \mathrm{~d}$ and e). These results indicate that the dopamine reuptake blocker works only if there is ambient dopamine.

\section{DISCUSSION}

The current study using isolated neurons provides solid evidence that: (1) ethanol at clinically relevant concentrations $(10-80 \mathrm{mM})$ facilitates glutamatergic transmission to VTA DAergic neurons, (2) although ethanol facilitation has a presynaptic locus, it is mediated not by the direct activation of the presynaptic $D_{1} R s$, but by the retrograde messenger dopamine, which is released from somatodendritic area and travels backward across synapses to facilitate glutamatergic neurotransmission by the activation of the $D_{1} R s$ on the glutamatergic terminals, and (3) ethanol facilitation of glutamate transmission to VTA DAergic neurons can occur in a preparation containing only a postsynaptic neuron and attached glutamatergic synapses.

Of note, in keeping with our recent result from brain slices, the single cell data show that ethanol enhances glutamatergic EPSCs at concentrations close to the blood alcohol levels observed in rats after voluntary ethanol consumption (Robinson et al, 2000; Doyon et al, 2003, 

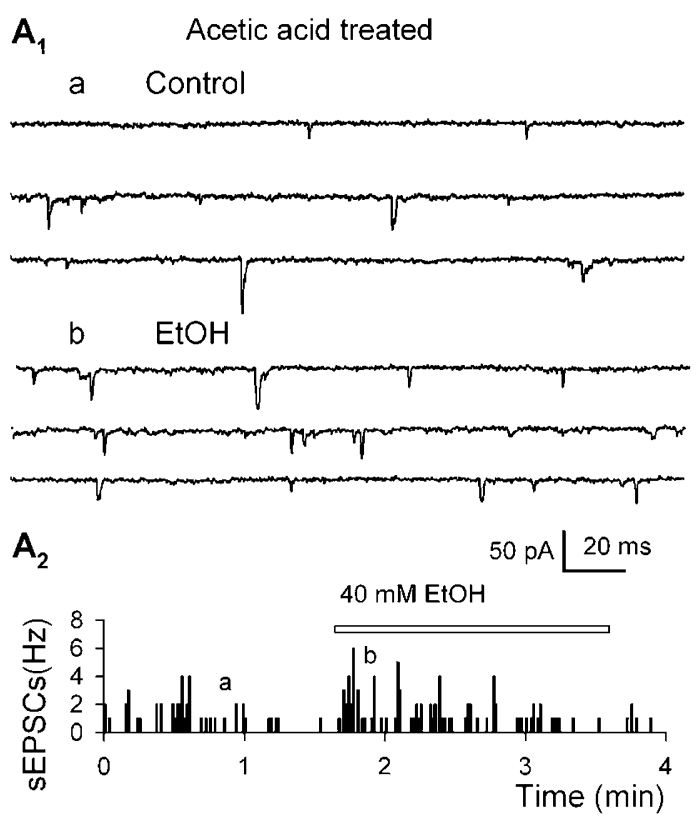

Postsynaptic membrane depolarization

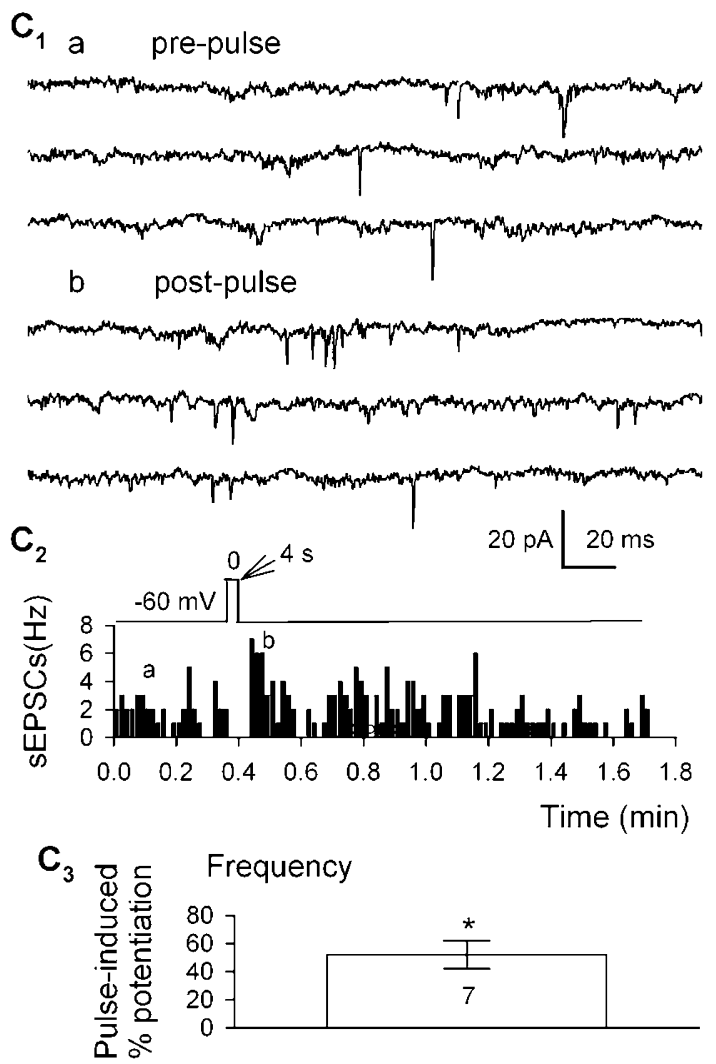

$$
\begin{gathered}
\text { B Reserpine treated } \\
\text { a Control }
\end{gathered}
$$
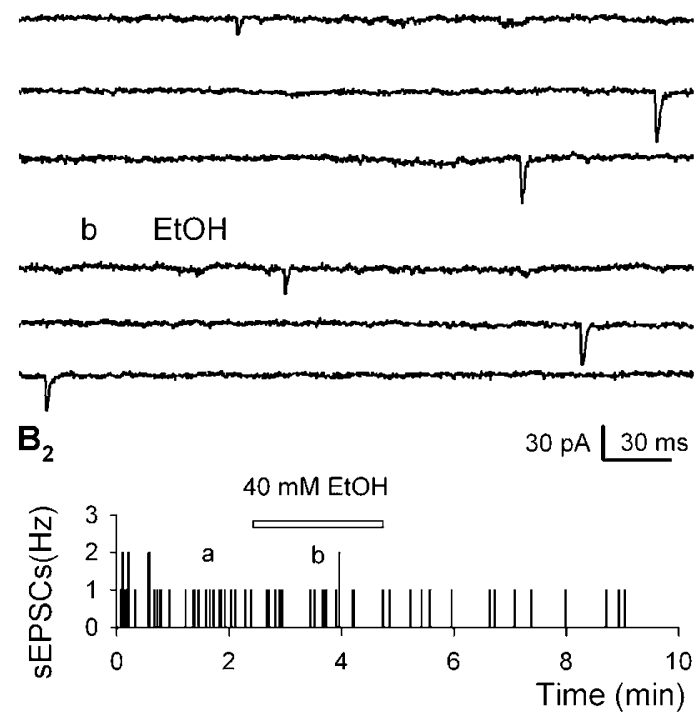

BAPTA $(20 \mathrm{mM})$ in pipette solution

$\mathbf{D}_{1}$ a Control
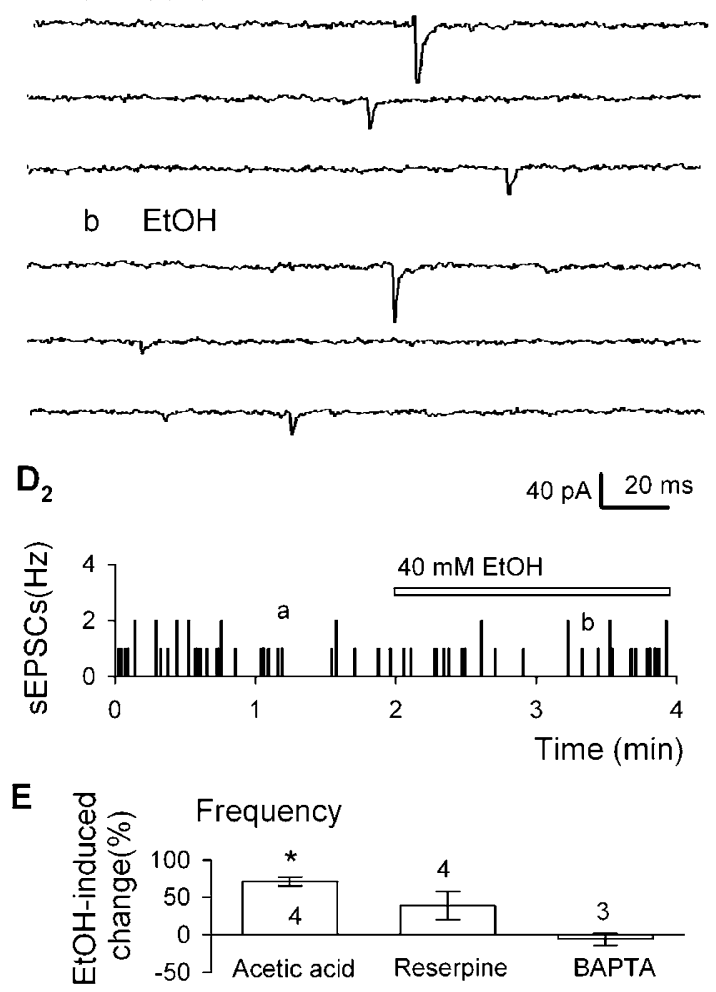

Figure 6 The release of dopamine is necessary for ethanol's facilitation of sEPSCs. $\left(A_{1}, B_{1}\right)$ Current traces show that ethanol enhancement of sEPSCs was observed in neurons from slices pretreated with acetic acid $\left(A_{1}\right)$, but not from reserpine $\left(B_{1}\right)$. $\left(A_{2}, B_{2}\right)$ Time course of ethanol-induced change of sEPSC frequency in one experiment. The traces in $\mathrm{AI}$ and $\mathrm{BI}$ were taken at times indicated by $(\mathrm{a})$ and $(\mathrm{b})$. $\left(\mathrm{C}_{1}\right)$ Current traces show that a $4 \mathrm{~s}$ depolarization pulse (from -60 to $0 \mathrm{mV}$ ) increased sEPSC frequency. $\left(C_{2}\right)$ Time course of depolarization-induced changes of sEPSC frequency in one experiment. $\left(C_{3}\right)$ Mean data ( \pm SEM, from seven neurons) show depolarization induced potentiation of sEPSC frequency. $* p<0.05$, paired $t$-test for postpulse vs prepulse control. (D) Current traces show that $40 \mathrm{mM}$ ethanol did not change the sEPSCs when the pipette solution contained $20 \mathrm{mM}$ BAPTA. (D2) Time course of $40 \mathrm{mM}$ ethanol-induced changes of sEPSC frequency in one experiment in which BAPTA was in the pipette solution. (E) Mean data ( \pm SEM) show changes in sEPSC frequency induced by $40 \mathrm{mM}$ ethanol under different experimental conditions. $* 0<0.05$, paired $t$-test for ethanol application vs pre-ethanol control, or as indicated, nonpaired t-test for reserpine group vs reserpine + ethanol group. 
a
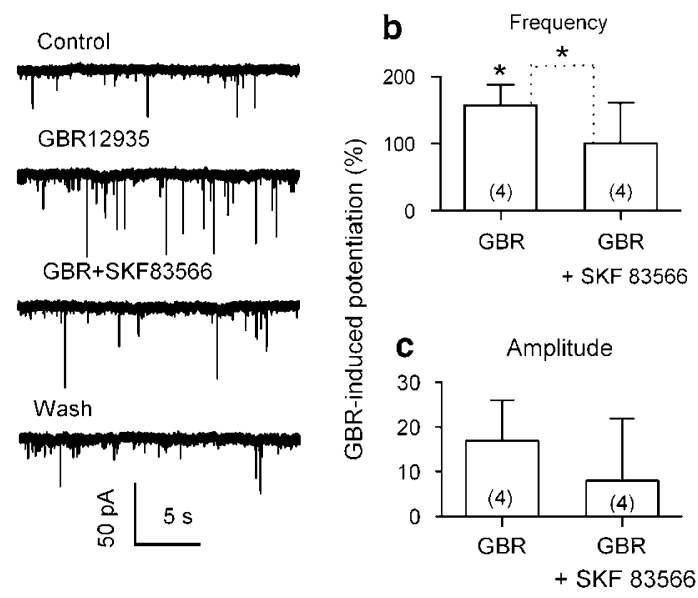

d $\quad$ BAPTA $(20 \mathrm{mM})$ in pipetter solution Control

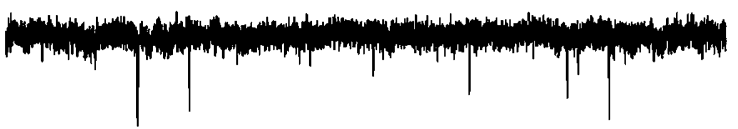

GBR 12935
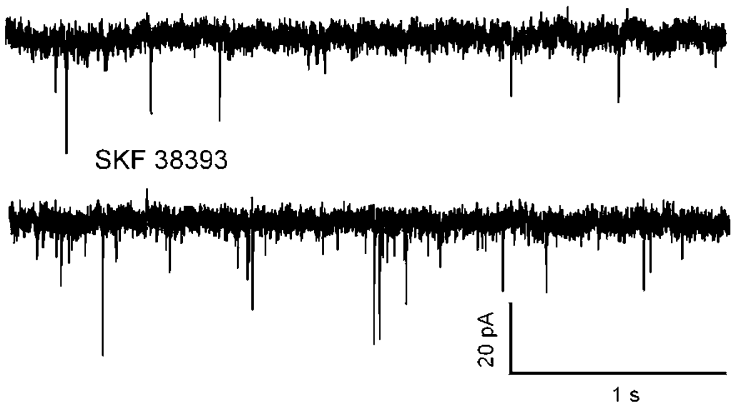

e

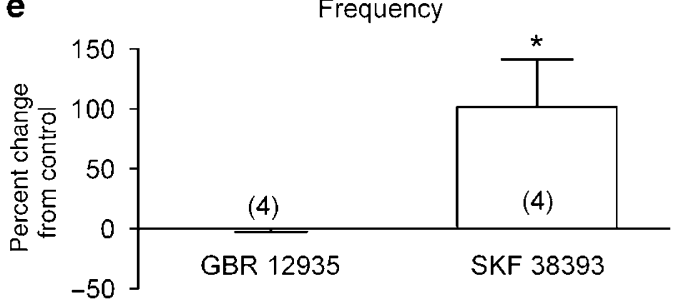

Figure 7 Ethanol-induced increase in sEPSC frequency is mimicked by blocking dopamine transport. (a) Traces illustrating increase in sEPSC frequency produced by GBR I 2935 ( I $\mu$ M, a dopamine transport blocker), which is blocked by the $D_{1} R$ antagonist SKF $83566(10 \mu M, n=4)$. (b) Summary of GBR 12935 -induced changes in sEPSC frequency, which was blocked by SKF 83566 (data from four cells). $* p<0.05$, paired $t$-test for GBR 12935 application vs pre-GBR 12935, or as indicated for GBR 12935 group vs GBR 12935 + SKF 83566. (c) No change in amplitude was seen in GBR I 2935 either in the absence or the presence of $10 \mu$ M SKF 83566. (d) Traces illustrating increase in sEPSC frequency produced by $10 \mu \mathrm{M}$ SKF 38393 but not by I $\mu$ M GBR 12935 when 20 mM BAPTA was in the pipette solution. (e) Mean data ( \pm SEM, from four neurons) show that SKF 38393, but not GBR 12935, increased sEPSC frequency when pipette solution contained $20 \mathrm{mM}$ BAPTA. * $p<0.05$, paired t-test for SKF 38393 application vs pre-SKF 38393.

2005). As glutamatergic transmission is an important mediator of behavioral changes caused by ethanol (Eckardt et al, 1998), we propose that this somatodendritic dopamine-mediated increased glutamate release in the VTA could be an important aspect of alcohol addiction.

\section{Ethanol Facilitates Glutamatergic Transmission in Single VTA DAergic Neurons}

In contrast to the suppression effects ethanol has on the neurons in many of the brain areas, previous studies have shown that ethanol can excite the VTA DAergic neurons (Gessa et al, 1985; Brodie et al, 1990). The mechanism underlying this excitatory effect of ethanol is not well understood, but it may contribute to the addictive property of ethanol and thus is a rapidly growing area of research in the neuroscience community. Ethanol may excites the DAergic neurons directly (Brodie et al, 1999b), by an enhancement of the hyperpolarization-activated current (Okamoto et al, 2006), and/or by an inhibition of the $\mathrm{M}$ channel (Koyama et al, 2007). Nevertheless, recent studies from this and other laboratories have shown that ethanol may excite VTA DAergic neurons indirectly, by an inhibition of the GABAergic transmission (Stobbs et al, 2004; Xiao et al, 2007; Xiao and Ye, 2008; but see Theile et al (2008) who reported that ethanol increases GABAergic transmission onto VTA DAergic neurons), and by an enhancement of the glutamatergic transmission to the VTA DAergic neurons (see below for more; Xiao et al, 2008).

Glutamate is the most abundant excitatory neurotransmitter in the brain, mediating as much as $70 \%$ of synaptic transmission within the CNS. Glutamate is important in drug addition and alcoholism (Gass and Olive, 2008). Most previous studies found that ethanol inhibits NMDA and nonNMDA glutamate receptors (Lovinger et al, 1989; Weitlauf and Woodward, 2008), as well as glutamate release (Siggins et al, 2005). In a recent study in midbrain slices, however, we demonstrated that acute ethanol facilitates glutamatergic transmission to VTA DAergic neurons (Xiao et al, 2008). In the current investigation in isolated neurons, we offer further support for ethanol potentiation of glutamate transmission to VTA DAergic neurons. This is the first electrophysiological evidence demonstrating a potentiating effect of acute ethanol on glutamatergic transmission in single cells.

Note that the effect of ethanol on sEPSC frequency is larger in isolated neurons than in slices. For example, $40 \mathrm{mM}$ ethanol increased sEPSC frequency by $\geqslant 77 \%$ in single cells, whereas the same concentration of ethanol increased sEPSC frequency by $50 \%$ in brain slices. We hypothesize that this results from a more efficient space clamping of isolated neurons and much faster and more complete exchange of the surrounding solution. Ethanol application is much more rapid in the isolated neurons, and there may be less time for the development of tolerance. In addition, a much greater role of reuptake in dopamine clearance in slices than in isolated neurons may also contribute to the difference (Brodie et al, 1999a).

It has been well documented that glutamatergic afferents of the VTA DAergic neurons comprise abundant neurons within a large formation extending from the prefrontal cortex to the caudal brainstem (Geisler et al, 2007). In addition, there are glutamatergic neurons in the VTA (Yamaguchi et al, 2007). Furthermore, DAergic neurons release glutamate as a cotransmitter with dopamine (Trudeau, 2004; Descarries et al, 2007). Future studies should identify the source of the glutamatergic afferents of 
the VTA DAergic neurons, which is responsible for ethanol facilitation.

\section{Ethanol Acts Presynaptically to Enhance Glutamatergic Transmission to Single VTA DAergic Neurons}

In keeping with our recent observation in brain slices (Xiao et al, 2008), in the current investigation in isolated neurons, we showed that ethanol increased the frequency of sEPSCs but had no effect on the amplitude of mEPSCs and of sEPSCs, indicating that ethanol acts on the presynaptic site to increase glutamate release. A possible explanation for the unusual positive action on glutamate release - which is in contrast to the more common depressant actions (Siggins et al, 2005) - would be an indirect mechanism, based on the special organization of the VTA, whose DAergic neurons receive dopamine (released from the somatodendritic area) and glutamate (released from glutamate-releasing terminals) of particular importance is the presence of $D_{1} R s$ on the glutamatergic axons.

Of note, a recent study shows that the DAergic cells in the substantia nigra make chemical DAergic synapses on one another (Vandecasteele et al, 2008). Perhaps VTA DAergic cells do as well. That is, the dopamine, which activates the presynaptic $D_{1}$ Rs could be released from the somatodendritic areas of the adjacent DAergic neuron, instead of the same DAergic neuron. However, ethanol facilitation was blocked by chelating postsynaptic calcium with BAPTA, indicating that the dopamine released from adjacent neuron, if it exists, may not have major function in ethanol facilitation of glutamate transmission in the VTA.

\section{Ethanol Enhances Glutamate Release in Single Cells by $\mathrm{D}_{1} \mathrm{R}$ Activation}

This notion is supported by the following evidence. The ethanol-induced increase in sEPSC frequency was eliminated by a $D_{1}$ antagonist. Moreover, like ethanol, a $D_{1}$ agonist increased the frequency of sEPSCs and mEPSCs without affecting their amplitude; a similar effect was produced by an increase in endogenous dopamine, induced by a blocker of dopamine reuptake. All these changes were abolished by the $\mathrm{D}_{1}$ antagonist.

Our data also suggest a crucial involvement of somatodendritic released dopamine, because ethanol's action was suppressed when endogenous monoamines (including dopamine) were depleted by reserpine, or when the postsynaptic $\mathrm{Ca}^{2+}$ was chelated by BAPTA $(20 \mathrm{mM})$. In addition, these data indicate that blocking dopamine reuptake may not be the major player in ethanol facilitation of sEPSCs, although previous in vivo studies suggested that ethanol may raise extracellular dopamine by blocking dopamine reuptake (Campbell et al, 1996; Yan et al, 2005).

A rise in local dopamine levels is also suggested by the bell-shaped dose-dependence of ethanol's action, both in our experiments (both in slices and in single cells) and in the in vivo experiments of Rodd et al (2004). This may result from opposite effects of dopamine (the nonselective endogenous agonist) acting on different receptors. At low concentration, dopamine appears to bind predominantly to $\mathrm{D}_{1} \mathrm{Rs}$ and at higher concentrations to $\mathrm{D}_{2} \mathrm{Rs}$. Thus, Trantham-Davidson et al (2004) found that low concentrations of dopamine $(<0.5 \mu \mathrm{M})$ enhanced IPSCs by activating mainly $\mathrm{D}_{1}$ Rs; whereas higher concentrations of dopamine $(>1 \mu \mathrm{M})$ reduced IPSCs by predominantly activating $\mathrm{D}_{2}$ Rs. Similarly, Alberto et al (2006) found that a low dose of dopamine $(1 \mu \mathrm{M})$ increased mEPSC frequency by activating $D_{1}$ Rs; whereas higher doses of dopamine (10$100 \mu \mathrm{M})$ decreased mEPSC frequency by activating $\mathrm{D}_{2}$ Rs. In comparable experiments on VTA and globus pallidus, Koga and Momiyama (2000) and Hernandez et al (2007) found that dopamine or a $\mathrm{D}_{2}$ agonist inhibits EPSCs in DAergic neurons through presynaptic $\mathrm{D}_{2} \mathrm{Rs}$ (in VTA, with a high $\mathrm{IC}_{50}$ of $16 \mu \mathrm{M}$ for dopamine). That the bell-shaped concentration dependence of ethanol's action is resulting from opposite presynaptic actions by $D_{1} R s$ and then $D_{2} R s$ is strongly supported by our finding in slices that the facilitation of sEPSCs by $80 \mathrm{mM}$ ethanol was greatly potentiated when $\mathrm{D}_{2}$ Rs were blocked (Xiao et al, 2008).

\section{Dopamine Reuptake Blocker (GBR 12935) Enhances Glutamate Release in Isolated VTA DAergic Neurons}

The application of GBR 12935 facilitates sEPSC frequency in single isolated DAergic neurons. This observation has specific significance to the mechanism underlying somatodendritic release of dopamine.

At the axon terminal, dopamine is stored in vesicles and released exocytotically. In the dendrite/soma, traditional secretory vesicles are scarce. Because synaptic sites and classic vesicular storage are uncommon in somatodendritic areas, some investigators have questioned whether somatodendritic dopamine is released exocytotically. Hallmarks of exocytotic release include sensitivity to $\mathrm{Ca}^{2+}$ concentration, $\mathrm{Na}^{+}$channel blockade, and neuronal vesicular monoamine transporter inhibition. Several studies have shown that somatodendritic dopamine release obeys these ionic requirements (Geffen et al, 1976; Cheramy et al, 1981; Kalivas and Duffy, 1991; Rice et al, 1994). However, nonexocytotic mechanisms of somatodendritic dopamine release have also been suggested, including reversal of the dopamine transporter (DAT; Nirenberg et al, 1996; Falkenburger et al, 2001). Nevertheless, a recent study found that dopamine could be measured in VTA slices from DAT knockout mice, and that the mechanisms governing electrically evoked somatodendritic dopamine release mechanisms are similar between DAT knockout and C57BL/6 mice (John and Jones, 2006). These data support an exocytotic mechanism for dopamine release in the VTA. This is also supported by a recent study suggesting that somatodendritic dopamine transmission is more analogous to classical synaptic transmission than previously believed (Beckstead et al, 2004). In isolated neurons, we found that GBR 12935 significantly increased sEPSC frequency. Higher concentrations of GBR 12935 may have effects other than blocking dopamine reuptake. However, this is unlikely as the facilitation of sEPSCs induced by GBR 12935 was blocked by a $D_{1} R$ antagonist. Thus, our results using GBR 12935 provide strong support for the exocytotic mechanism of somatodendritic dopamine release in the VTA.

In conclusion, this study provides evidence from single isolated VTA DAergic neurons that ethanol facilitation results from increased somatodendritic dopamine release, which retrogradely activates the $\mathrm{D}_{1} \mathrm{Rs}$ on glutamate- 
releasing terminals. These results demonstrate that ethanol stimulation of a single cell is capable of eliciting the release of dopamine, which is sufficient to influence glutamatergic transmission at individual synapses. Given that excitatory afferents regulate the activity of DAergic neurons, the release of dopamine is essential for the development of addiction (Kalivas and Duffy, 1995), and ethanol facilitation of glutamate release might contribute to its reward property. Our findings indicate that somatodendritic dopamine release is crucial in modulating the activity of DAergic neurons and in the rewarding effect of ethanol, and thus a key target of ethanol. Furthermore, the current study also demonstrates a powerful tool for pharmacological and physiological studies of dopamine signaling in the VTA.

\section{ACKNOWLEDGEMENTS}

This work was made possible by NIH grants AA015925, AA016964 (JHY), and the UMDNJ foundation (JHY). We thank Dr Cheng Xiao and Dr David Lovinger for their helpful comments for this work.

\section{DISCLOSURE/CONFLICT OF INTEREST}

The authors declare no conflict of interest.

\section{REFERENCES}

Abarca J, Gysling K, Roth RH, Bustos G (1995). Changes in extracellular levels of glutamate and aspartate in rat substantia nigra induced by dopamine receptor ligands: in vivo microdialysis studies. Neurochem Res 20: 159-169.

Adell A, Artigas F (2004). The somatodendritic release of dopamine in the ventral tegmental area and its regulation by afferent transmitter systems. Neurosci Biobehav Rev 28: 415-431.

Aghajanian GK, Bunney BS (1977). Pharmacological characterization of dopamine 'autoreceptors' by microiontophoretic singlecell recording studies. Adv Biochem Psychopharmacol 16: 433-438.

Akaike N, Moorhouse AJ (2003). Techniques: applications of the nerve-bouton preparation in neuropharmacology. Trends Pharmacol Sci 24: 44-47.

Alberto CO, Trask RB, Quinlan ME, Hirasawa M (2006). Bidirectional dopaminergic modulation of excitatory synaptic transmission in orexin neurons. J Neurosci 26: 10043-10050.

Balmforth AJ, Warburton P, Ball SG (1990). Homologous desensitization of the D1 dopamine receptor. J Neurochem 55: 2111-2116.

Beckstead MJ, Grandy DK, Wickman K, Williams JT (2004). Vesicular dopamine release elicits an inhibitory postsynaptic current in midbrain dopamine neurons. Neuron 42: 939-946.

Bjorklund A, Lindvall O (1975). Dopamine in dendrites of substantia nigra neurons: suggestions for a role in dendritic terminals. Brain Res 83: 531-537.

Bormann J, Hamill OP, Sakmann B (1987). Mechanism of anion permeation through channels gated by glycine and gammaaminobutyric acid in mouse cultured spinal neurones. J Physiol 385: 243-286.

Brodie MS, McElvain MA, Bunney EB, Appel SB (1999a). Pharmacological reduction of small conductance calciumactivated potassium current (SK) potentiates the excitatory effect of ethanol on ventral tegmental area dopamine neurons. J Pharmacol Exp Ther 290: 325-333.
Brodie MS, Pesold C, Appel SB (1999b). Ethanol directly excites dopaminergic ventral tegmental area reward neurons. Alcohol Clin Exp Res 23: 1848-1852.

Brodie MS, Shefner SA, Dunwiddie TV (1990). Ethanol increases the firing rate of dopamine neurons of the rat ventral tegmental area in vitro. Brain Res 508: 65-69.

Cameron DL, Williams JT (1993). Dopamine D1 receptors facilitate transmitter release. Nature 366: 344-347.

Campbell AD, Kohl RR, McBride WJ (1996). Serotonin-3 receptor and ethanol-stimulated somatodendritic dopamine release. Alcohol 13: 569-574.

Cheramy A, Leviel V, Glowinski J (1981). Dendritic release of dopamine in the substantia nigra. Nature 289: 537-542.

Cragg SJ, Greenfield SA (1997). Differential autoreceptor control of somatodendritic and axon terminal dopamine release in substantia nigra, ventral tegmental area, and striatum. J Neurosci 17: $5738-5746$.

Descarries L, Berube-Carriere N, Riad M, Bo GD, Mendez JA, Trudeau LE (2007). Glutamate in dopamine neurons: synaptic $v s$ diffuse transmission. Brain Res Rev.

Doyon WM, Anders SK, Ramachandra VS, Czachowski CL, Gonzales RA (2005). Effect of operant self-administration of $10 \%$ ethanol plus $10 \%$ sucrose on dopamine and ethanol concentrations in the nucleus accumbens. J Neurochem 93: 1469-1481.

Doyon WM, York JL, Diaz LM, Samson HH, Czachowski CL, Gonzales RA (2003). Dopamine activity in the nucleus accumbens during consummatory phases of oral ethanol self-administration. Alcohol Clin Exp Res 27: 1573-1582.

Eckardt MJ, File SE, Gessa GL, Grant KA, Guerri C, Hoffman PL et al (1998). Effects of moderate alcohol consumption on the central nervous system. Alcohol Clin Exp Res 22: 998-1040.

Falkenburger BH, Barstow KL, Mintz IM (2001). Dendrodendritic inhibition through reversal of dopamine transport. Science 293: 2465-2470.

Ford CP, Mark GP, Williams JT (2006). Properties and opioid inhibition of mesolimbic dopamine neurons vary according to target location. J Neurosci 26: 2788-2797.

Gass JT, Olive MF (2008). Glutamatergic substrates of drug addiction and alcoholism. Biochem Pharmacol 75: 218-265.

Geffen LB, Jessell TM, Cuello AC, Iversen LL (1976). Release of dopamine from dendrites in rat substantia nigra. Nature 260: 258-260.

Geisler S, Derst C, Veh RW, Zahm DS (2007). Glutamatergic afferents of the ventral tegmental area in the rat. J Neurosci 27: $5730-5743$.

Gessa GL, Muntoni F, Collu M, Vargiu L, Mereu G (1985). Low doses of ethanol activate dopaminergic neurons in the ventral tegmental area. Brain Res 348: 201-203.

Grace AA (1990). Evidence for the functional compartmentalization of spike generating regions of rat midbrain dopamine neurons recorded in vitro. Brain Res 524: 31-41.

Hernandez A, Sierra A, Valdiosera R, Floran B, Erlij D, Aceves J (2007). Presynaptic D1 dopamine receptors facilitate glutamatergic neurotransmission in the rat globus pallidus. Neurosci Lett 425: 188-191.

Iravani MM, Muscat R, Kruk ZL (1996). Comparison of somatodendritic and axon terminal dopamine release in the ventral tegmental area and the nucleus accumbens. Neuroscience 70: $1025-1037$.

Jang IS, Nakamura M, Ito Y, Akaike N (2006). Presynaptic GABAA receptors facilitate spontaneous glutamate release from presynaptic terminals on mechanically dissociated rat CA3 pyramidal neurons. Neuroscience 138: 25-35.

John CE, Jones SR (2006). Exocytotic release of dopamine in ventral tegmental area slices from C57BL/6 and dopamine transporter knockout mice. Neurochem Int 49: 737-745. 
Jones S, Kauer JA (1999). Amphetamine depresses excitatory synaptic transmission via serotonin receptors in the ventral tegmental area. J Neurosci 19: 9780-9787.

Kalivas PW, Duffy P (1991). A comparison of axonal and somatodendritic dopamine release using in vivo dialysis. J Neurochem 56: 961-967.

Kalivas PW, Duffy P (1995). D1 receptors modulate glutamate transmission in the ventral tegmental area. J Neurosci 15: 5379-5388.

Koga E, Momiyama T (2000). Presynaptic dopamine D2-like receptors inhibit excitatory transmission onto rat ventral tegmental dopaminergic neurones. J Physiol 523(Part 1): 163-173.

Koyama S, Brodie MS, Appel SB (2007). Ethanol inhibition of mcurrent and ethanol-induced direct excitation of ventral tegmental area dopamine neurons. J Neurophysiol 97: 1977-1985.

Lacey MG, Mercuri NB, North RA (1989). Two cell types in rat substantia nigra zona compacta distinguished by membrane properties and the actions of dopamine and opioids. J Neurosci 9: $1233-1241$.

Llinas R, Greenfield SA, Jahnsen H (1984). Electrophysiology of pars compacta cells in the in vitro substantia nigra - a possible mechanism for dendritic release. Brain Res 294: 127-132.

Lovinger DM, White G, Weight FF (1989). Ethanol inhibits NMDAactivated ion current in hippocampal neurons. Science 243: 1721-1724.

Lu X, Hagg T (1997). Glial cell line-derived neurotrophic factor prevents death, but not reductions in tyrosine hydroxylase, of injured nigrostriatal neurons in adult rats. J Comp Neurol 388: 484-494.

Margolis EB, Lock H, Hjelmstad GO, Fields HL (2006). The ventral tegmental area revisited: is there an electrophysiological marker for dopaminergic neurons? J Physiol 577: 907-924.

Melis M, Pistis M, Perra S, Muntoni AL, Pillolla G, Gessa GL (2004). Endocannabinoids mediate presynaptic inhibition of glutamatergic transmission in rat ventral tegmental area dopamine neurons through activation of $\mathrm{CB} 1$ receptors. J Neurosci 24: 53-62.

Memo M, Lovenberg W, Hanbauer I (1982). Agonist-induced subsensitivity of adenylate cyclase coupled with a dopamine receptor in slices from rat corpus striatum. Proc Natl Acad Sci USA 79: 4456-4460.

Nirenberg MJ, Chan J, Liu Y, Edwards RH, Pickel VM (1996). Ultrastructural localization of the vesicular monoamine transporter-2 in midbrain dopaminergic neurons: potential sites for somatodendritic storage and release of dopamine. J Neurosci 16: 4135-4145.

Okamoto T, Harnett MT, Morikawa H (2006). Hyperpolarizationactivated cation current $\left(I_{\mathrm{h}}\right)$ is an ethanol target in midbrain dopamine neurons of mice. J Neurophysiol 95: 619-626.

Overton PG, Clark D (1997). Burst firing in midbrain dopaminergic neurons. Brain Res Brain Res Rev 25: 312-334.

Reith ME, Xu C, Chen NH (1997). Pharmacology and regulation of the neuronal dopamine transporter. Eur J Pharmacol 324: 1-10.

Rice ME, Richards CD, Nedergaard S, Hounsgaard J, Nicholson C, Greenfield SA (1994). Direct monitoring of dopamine and 5-HT release in substantia nigra and ventral tegmental area in vitro. Exp Brain Res 100: 395-406.

Robinson DL, Lara JA, Brunner LJ, Gonzales RA (2000). Quantification of ethanol concentrations in the extracellular fluid of the rat brain: in vivo calibration of microdialysis probes. J Neurochem 75: 1685-1693.

Rodd ZA, Melendez RI, Bell RL, Kuc KA, Zhang Y, Murphy JM et al (2004). Intracranial self-administration of ethanol within the ventral tegmental area of male Wistar rats: evidence for involvement of dopamine neurons. J Neurosci 24: 1050-1057.

Schilstrom B, Yaka R, Argilli E, Suvarna N, Schumann J, Chen BT et al (2006). Cocaine enhances NMDA receptor-mediated currents in ventral tegmental area cells via dopamine D5 receptor-dependent redistribution of NMDA receptors. $J \mathrm{Neu}$ rosci 26: 8549-8558.

Siggins GR, Roberto M, Nie Z (2005). The tipsy terminal: presynaptic effects of ethanol. Pharmacol Ther 107: 80-98.

Stobbs SH, Ohran AJ, Lassen MB, Allison DW, Brown JE, Steffensen SC (2004). Ethanol suppression of ventral tegmental area GABA neuron electrical transmission involves $N$-methyl-Daspartate receptors. J Pharmacol Exp Ther 311: 282-289.

Tepper JM, Sawyer SF, Groves PM (1987). Electrophysiologically identified nigral dopaminergic neurons intracellularly labeled with HRP: light-microscopic analysis. J Neurosci 7: 2794-2806.

Tepper JM, Sun BC, Martin LP, Creese I (1997). Functional roles of dopamine D2 and D3 autoreceptors on nigrostriatal neurons analyzed by antisense knockdown in vivo. J Neurosci 17: 2519-2530.

Theile JW, Morikawa H, Gonzales RA, Morrisett RA (2008). Ethanol enhances GABAergic transmission onto dopamine neurons in the ventral tegmental area of the rat. Alcohol Clin Exp Res 32: 1040-1048.

Trantham-Davidson H, Neely LC, Lavin A, Seamans JK (2004). Mechanisms underlying differential D1 vs D2 dopamine receptor regulation of inhibition in prefrontal cortex. J Neurosci 24: 10652-10659.

Trudeau LE (2004). Glutamate co-transmission as an emerging concept in monoamine neuron function. J Psychiatry Neurosci 29: $296-310$.

Vandecasteele M, Glowinski J, Deniau JM, Venance L (2008). Chemical transmission between dopaminergic neuron pairs. Proc Natl Acad Sci USA 105: 4904-4909.

Weitlauf C, Woodward JJ (2008). Ethanol selectively attenuates NMDAR-mediated synaptic transmission in the prefrontal cortex. Alcohol Clin Exp Res 32: 690-698.

Xiao C, Ye JH (2008). Ethanol dually modulates GABAergic synaptic transmission onto dopaminergic neurons in ventral tegmental area: role of mu-opioid receptors. Neuroscience 153: 240-248.

Xiao C, Shao XM, Olive MF, Griffin III WC, Li KY, Krnjevic K et al (2008). Ethanol facilitates glutamatergic transmission to dopamine neurons in the ventral tegmental area. Neuropsychopharmacology.

Xiao C, Zhang J, Krnjevic K, Ye JH (2007). Effects of ethanol on midbrain neurons: role of opioid receptors. Alcohol Clin Exp Res 31: 1106-1113.

Yamaguchi T, Sheen W, Morales M (2007). Glutamatergic neurons are present in the rat ventral tegmental area. Eur J Neurosci 25: 106-118.

Yamanaka H, Doi A, Ishibashi H, Akaike N (2002). Aconitine facilitates spontaneous transmitter release at rat ventromedial hypothalamic neurons. Br J Pharmacol 135: 816-822.

Yan QS, Zheng SZ, Feng MJ, Yan SE (2005). Involvement of 5HT1B receptors within the ventral tegmental area in ethanolinduced increases in mesolimbic dopaminergic transmission. Brain Res 1060: 126-137.

Ye JH, Wang F, Krnjevic K, Wang W, Xiong ZG, Zhang J (2004). Presynaptic glycine receptors on GABAergic terminals facilitate discharge of dopaminergic neurons in ventral tegmental area. J Neurosci 24: 8961-8974.

Ye JH, Zhang J, Xiao C, Kong JQ (2006). Patch-clamp studies in the CNS illustrate a simple new method for obtaining viable neurons in rat brain slices: glycerol replacement of $\mathrm{NaCl}$ protects $\mathrm{CNS}$ neurons. J Neurosci Methods 158: 251-259.

Zhou C, Xiao C, McArdle JJ, Ye JH (2006). Mefloquine enhances nigral gamma-aminobutyric acid release via inhibition of cholinesterase. J Pharmacol Exp Ther 317: 1155-1160.

Zhu PJ, Lovinger DM (2005). Retrograde endocannabinoid signaling in a postsynaptic neuron/synaptic bouton preparation from basolateral amygdala. J Neurosci 25: 6199-6207. 